\title{
Vulnerability Analysis of Urban Rail Transit Network within Multi-Modal Public Transport Networks
}

\author{
Qing-Chang Lu* and Shan Lin \\ Department of Traffic Information and Control, School of Electronic and Control Engineering, \\ Chang'an University, Middle-Section, Nan'er Huan Rd., Xi'an 710064, Shaanxi, China; linshan@chd.edu.cn \\ * Correspondence: qclu@chd.edu.cn; Tel./Fax: +86-29-82334719
}

Received: 17 March 2019; Accepted: 3 April 2019; Published: 9 April 2019

\begin{abstract}
In terms of urban rail transit network vulnerability, most studies have focused on the network topology characteristics and travel cost changes after network incidents and analyzed rail transit network independently. The neglects of passenger flow distributions on the network and alternative public transport modes under rail network disruptions would either underestimate or overestimate the vulnerability of rail transit network, and thus lead to inaccurate results and decisions. This study presents an accessibility-based measurement for urban rail transit network vulnerability analysis and explicitly accounts for rail passenger flow characteristics, travel cost changes, and alternative transit modes. It is shown that the proposed approach is capable of measuring the consequences on rail network, and the advantages of the accessibility method are demonstrated and compared. The methodology is applied to the urban rail transit network of Shenzhen, China within a multi-modal public transport network. Results reveal that the consequences of disruptions on network accessibility are obviously different for stations with different passenger flow characteristics, and some undisrupted stations are found to be vulnerable under surrounding station failures. The proposed methodology offers reliable measurements on rail transit network vulnerability and implications for decision-making under rail network disruptions.
\end{abstract}

Keywords: urban rail transit vulnerability; multi-modal transit network; accessibility; network interdependency; disruptions

\section{Introduction}

Urban rail transit, especially in mega cities, is playing an essential role in people's daily intra-city travels. With ever-increasing passenger flows, urban rail transit becomes more and more important, particularly in cities such as Shanghai and Beijing, China, where urban rail transit is undergoing rapid development. It was announced by Shanghai Rail and Beijing Municipal Commission of Transport in March 2016 that daily rail transit passenger flows exceed 10 million in the two cities. This number is expected to increase with continuous rail transit network construction and ever-growing travel demand. Thus, the urban rail transit network has to be resilient and robust to provide reliable services for such a large population every day. Any type of incident on the rail transit network will pose a great threat to people's daily travel, making the rail network vulnerable [1,2]. The impacts on commuters' travel decisions could even go beyond the direct travel time losses [3,4].

Consequently, there has been growing research interest in network vulnerability analysis in recent decades. Attention has been attracted to the vulnerability analysis of highway and urban road network under natural or man-made disruptions [5-9], and public transport network vulnerability has not been of much concern until recent years [1,10-13]. In case of failures, especially emergency disruptions, the public transport network would be more vulnerable than the road network because of its low 
network redundancy and large number of passengers that would be affected. This vulnerability is particularly highlighted for the urban rail transit network.

Although no agreement has been reached on the exact definition of transportation network vulnerability, the vulnerability methodology is now well established by addressing the probability of incidents (or exposure of the transportation network to disruptions) and consequence measures under disruptions. During the past decade, literature on transportation network vulnerability mainly contributes to the development of methodologies measuring consequences on network performance after disruption events. These methodologies could be categorized into the exposure-importance approach [5], accessibility measure [8,13-15], and game theory method [16] among others [6]. The above methods are mainly applied to road networks based on a network scan approach in the beginning $[14,17,18]$. Research then tried to overcome the disadvantage in computation time of the full scan method by either identifying links for further analysis based on certain criteria [12,19] or calculating the "impact area" of the affected link to downscale the network for analysis [20].

Different from the above vulnerability analysis of road networks, the network vulnerability of urban rail transit is usually studied based on complex network theories elaborating the network topology characteristics under incidents. Degree, betweenness, centrality measures, and connectivity are employed for the measurement of rail transit network vulnerability, robustness, and resilience [21-23]. A detailed presentation of measures in the literature is summarized by Mishra et al. [10]. This approach of vulnerability analysis would be important for the planning and design of the urban rail transit network. However, under disruptions, the vulnerability of the urban rail transit network might go beyond the issue of pure network topology and become a problem of a combination of network topology and passenger flow, especially considering the large number of passengers served [24]. As a result, another approach direction in urban transit network vulnerability analysis has been shaped recently, sharing a similar concept to the above road network vulnerability method. Based on total travel time and passenger flow on each link, De-Los-Santos et al. measured passengers' robustness under link and station failure by introducing with-bus-bridging and without-bus-bridging cases for the Madrid rail transit network [25]. A public transport network vulnerability approach was developed by Rodríguez-Núñez and García-Palomares [1] based on travel time and changes in trip distribution. The methodology was applied to the Madrid Rail system, and critical links and the importance of circular line were identified. Integrating betweenness centrality and dynamic costs of operators and passengers, Cats and Jenelius measured the public transport network vulnerability of Stockholm, Sweden revealing that betweenness centrality itself may not be a good indicator of link importance [26]. To evaluate the effectiveness of strategies reducing impacts of disruptions on public transport network, Cats and Jenelius proposed passenger utility measures quantifying network-wide impacts on rapid public transport networks of Stockholm, Sweden integrating passengers' stochastic dynamic route choice and supply and demand [11]. Recently, Cats et al. addressed the probability or exposure side of public transport network vulnerability, addressing passengers' exposure to link failures by elaborating the frequency and time duration of possible disruption events in the Netherlands [12].

As learnt from the above review, the majority of existing urban rail transit network vulnerability analysis methodologies is rooted in network and graph theory, neglecting the large population it carries $[9,10]$. Efforts have been made recently to include travel time, passenger flow, and link-based passenger exposure in transit network analysis. However, the importance of a link or station in terms of passenger volume is seldom considered in the vulnerability methodologies such as Rodríguez-Núñez and García-Palomares [1]. As concluded by Knoop et al., different links are found to be the most important based on different criteria used [19]. Failing to consider this would underestimate the vulnerability of links and stations that have small average travel time changes but a large number of passengers affected under disruptions. The inclusion of passenger importance is particularly essential for the vulnerability analysis of rail transit in developing countries with developing rail network and increasing trips. Most of the vulnerability literature focuses on the urban rail transit network 
in developed countries, which would have small passenger demand variation, and thus the results may not be applicable to developing countries with growing and changing rail ridership demand. In case of disruptions, people may not only want to know the vulnerability of the network but also the stations most affected or unaffected, however, such information is rarely provided in the literature. Methodologies of vulnerability analysis usually treat rail transit network independently without considering the interdependency nature between multi-modal urban transit networks in reality, which would overestimate the vulnerability of urban rail transit networks under disruptions. People could transfer to other public transport modes nearby if a rail transit station is failed or closed, and exclusion of this alternative in urban rail transit network vulnerability analysis may reach inaccurate results and conclusions.

In order to address the above research gaps, this study proposes and applies a unique location-based accessibility approach for the vulnerability analysis of the urban rail transit network. Unlike many previous studies on the vulnerability of public transport networks as well as the accessibility method for road network vulnerability, this study explicitly accounts for the importance of stations and transfers to other public transport modes under rail network disruptions. The proposed rail transit network vulnerability could not only be measured for station disruptions but also for link and line failures based on a combination of the accessibility method and graph theory approach. The proposed methodology is described in a step by step process in Section 2. To evaluate the accessibility-based methodology, an example problem is then presented demonstrating results of various vulnerability measures in Section 3. Section 4 shows a case study on Shenzhen urban rail transit network (SURTN), and a method of identifying candidate stations for a full scan analysis is used. Finally, Section 6 summarizes the findings of this research and concludes the paper.

\section{Methodology}

A significant body of literature has contributed to the development and improvement of accessibility for different purposes $[27,28]$. Accessibility is also proven to be an important measure for transportation network vulnerability analysis $[7,14,17]$ and mostly developed for applications on road network. The accessibility of the public transport network has recently attracted a lot of attention and has become an important interest in research [24,29]. We propose a transit accessibility method for measuring the vulnerability of rail transit network under disruptions. The method is developed for failures of stations, links, and/or lines. Normally, stations are more exposed and vulnerable to disruptions, as they have more complex passenger activities and infrastructure compositions and a higher probability of becoming terrorists' targets than links. The mathematical construct of the proposed methodology starts with a station-based accessibility measure as follows.

\subsection{Station-Based Urban Rail Transit Network Accessibility}

Under emergent rail transit network disruptions, passengers may reroute to unaffected lines to reach their destinations, but some passengers could find no alternative routes except for other public transport services such as ground bus and taxi within walkable distance. The mobility to choose alternative routes/modes and the accessibility to arrive at destinations are both reduced for rail transit passengers whose routes are affected. As a result, we measured the accessibility of these two situations separating the affected and unaffected stations, which has not been identified and addressed in previous studies.

Let $N$ be the set of all stations in a rail network. $N_{W} \subseteq N$ is the subset of working stations after disruption, and $N_{D}=N-N_{W}$ denotes the subset of station(s) disrupted. The location-based accessibility of station $i$ is formulated as

$$
A_{i}=\alpha S I_{i}^{0}\left(\frac{\sum_{j \in N_{W}} A R_{i j} F R_{i j}}{\sum_{j \in N_{W}} A R_{i j}^{0} F R_{i j}^{0}}\right)^{-1}+(1-\alpha) S I_{i}^{0}\left(\sum_{j \in N_{D}} B R_{j}\left(\frac{A R_{i j} F B_{i j}}{A R_{i j}^{0} F R_{i j}^{0}}\right)^{-1}\right)\left(i \neq j, i \in N_{W}\right)
$$


where $A_{i}$ denotes the accessibility of rail station $i, S I_{i}{ }^{0}$ represents station importance of rail station $i$ among all the stations, $A R^{0}{ }_{i j}$ is the passenger volume from rail station $j$ to station $i$ before network disruption, $A R_{i j}$ demonstrates the passenger volume from rail station $j$ to station $i$ after network disruption, $F R^{0}{ }_{i j}$ shows the travel cost of rail transit from station $j$ to station $i$ before network disruption, $F R_{i j}$ represents the travel cost of rail transit from station $j$ to station $i$ after network disruption, $F B_{i j}$ is the travel cost of ground bus from rail station $j$ to station $i$ after network disruption, $B R_{j}$ denotes the bus capacity ratio in terms of total passenger volume within walkable distance of rail station $j$, and $\alpha$ is the balance factor of $j$ between working stations and disrupted stations, and $\alpha=1$, if $j \in N_{W} ; \alpha=0$, if $j \in N_{D}$. This index follows similar structure of the Hansen accessibility index and measures the accessibility based on stations or locations, as a result it is named the location-based accessibility index.

The station importance is described as the total passenger flows using a station before network disruption, and the more passengers using this station the more important the station becomes. The station importance here is defined as passengers arriving and departing a station and constructed as

$$
\begin{gathered}
I_{i}^{0}=D E_{i}^{0}+A R_{i}^{0} \quad(i \in N) \\
S I_{i}^{0}=\frac{I_{i}^{0}}{\sum_{i \in N} I_{i}^{0}} \quad(i \in N)
\end{gathered}
$$

where $D E^{0}{ }_{i}$ is the total departure passenger volume at rail station $i$ before network disruption, representing the generation of station $i, A R^{0}{ }_{i}$ denotes the total arrival passenger volume at rail station $i$ before network disruption, showing the attractiveness of station $i$, and $I_{i}{ }^{0}$ represents the total passenger volume of station $i$.

The bus capacity ratio is defined as the ratio of number of bus stops within walkable distance of station $\mathrm{j}$ divided by the total passenger volume of this station to the maximum bus stops each passenger has within the study area, which is calculated as Equation (4).

$$
B R_{j}=\frac{B S_{j} / I_{j}^{0}}{\operatorname{Max}\left(B S_{j} / I_{j}^{0}\right)} \quad(j \in N)
$$

where $B S_{j}$ is the total bus stations within walkable distance of rail station $j$. This measures the relative capacity of buses to serve for the rail transit passengers under station disruptions. During rail station closures, people might take ground bus instead or to the nearest working rail stations regardless of the direction of bus services, as a result both bus directions are included. The frequency of bus services is the normal frequency since these buses are not run specifically for evacuating the rail passengers. In many cities, the ground bus services are operated by different companies, and the frequency of the services is hardly coordinated. Also, road traffic near disrupted rail stations is usually congested because of the affected rail passengers, and the scheduled frequency of bus services could not be guaranteed. This ratio measures the capacity of bus services accommodating delayed rail passengers.

As a result, the overall accessibility of working rail stations $A_{W}$ could be calculated as

$$
\begin{gathered}
A_{W}=\sum_{i \in N_{W}} A_{i}=\sum_{i \in N_{W}} \alpha S I_{i}^{0}\left(\frac{\sum_{j \in N_{W}} A R_{i j} F R_{i j}}{\sum_{j \in N_{W}} A R_{i j}^{0} F R_{i j}^{0}}\right)^{-1}+(1- \\
\alpha) S I_{i}^{0}\left(\sum_{j \in N_{D}} B R_{j}\left(\frac{A R_{i j} F B_{i j}}{A R_{i j}^{0} P R_{i j}^{0}}\right)^{-1}\right)(i \neq j)
\end{gathered}
$$

where $A_{W}$ is the overall accessibility of working stations.

For station $i N_{D}$, passengers could not reroute to unaffected rail transit lines but have to take other transit modes such as buses to reach station $i$. The accessibility of station $i$ is then proposed as

$$
A_{i}=S I_{i}^{0} B R_{i}\left(\frac{\sum_{j \in N} A R_{i j} F B_{i j}}{\sum_{j \in N} A R_{i j}^{0} F R_{i j}^{0}}\right)^{-1} \quad\left(i \neq j, i \in N_{D}\right)
$$


The accessibility of closed stations is equal to the accessibility summation of all the disrupted stations, which is

$$
A_{D}=\sum_{i \in N_{D}} A_{i}=\sum_{i \in N_{D}} S I_{i}^{0} B R_{i}\left(\frac{\sum_{j \in N} A R_{i j} F B_{i j}}{\sum_{j \in N} A R_{i j}^{0} F R_{i j}^{0}}\right)^{-1}(i \neq j)
$$

where $A_{D}$ is the total accessibility of disrupted stations.

\subsection{Urban Rail Transit Network Accessibility under Station(s) Failure}

Based on the interpretation of the above station-based accessibility, the network accessibility consists of the accessibility of working stations and disrupted stations. Thus, if rail station(s) $d$ is disrupted, the rail network accessibility could be formulated as

$$
A^{d}=A_{W}^{d}+A_{D}^{d}
$$

where $A^{d}$ is the rail network accessibility when station(s) $d$ is closed, $A^{d}{ }_{W}$ denotes the accessibility of all the working stations when station(s) $d$ is closed, $A^{d}{ }_{D}$ describes the accessibility of all the disrupted stations when station(s) $d$ is closed, and $d$ represents the station or set of stations failed, and is non-negative integer.

Equation (8) calculates the rail transit network accessibility under station failure while including the availability and capacity of ground bus transportation for closed stations. This calculation allows no station failure scenario, that is, $d=0$ as well as single and multiple station disruptions. Partial station failure could also be included in this methodology when separating arrival and departure passenger volumes of closed and working lines at a station. Another advantage of this method is that if $d=N$ most current vulnerability measures would have network performance values of zero since all the stations are disrupted, but in reality, this is not the case and passengers could still travel with other transit modes, which could be addressed with the proposed accessibility measure.

\subsection{Urban Rail Transit Network Accessibility under Link(s) Failure}

In rail transit network, rail stations and links are interdependent with each other. Particularly in an emergency, incidences or disruptions on two stations or any parts between two stations of a link would either result in failure of the link or postponing of the line containing this link. Thus, the network accessibility under link disruption is interpreted based on the network accessibility under station failure proposed above. In case of disruptions on link of rail transit network, if stations at the two ends of the link are also included, the network accessibility under link failure is constructed as

$$
A^{L}=A^{d}, D C_{d}=\operatorname{Max}\left(D C_{m}, D C_{n}\right)\left(m, n \in N_{L}\right)
$$

where $A^{L}$ denotes the rail network accessibility when link $L$ is failed, $D C_{m}$ represents the degree centrality of disrupted station $m$, which is calculated as the number of direct connections of $m$ with other stations, $m$ and $n$ are disrupted stations of link $l$, and $N_{L}$ represents the station set of link $l$. If only link disruption is considered, the network accessibility under link failure is equal to the accessibility of station failure, which only belongs to the line containing this link. The network accessibility under link failure could be described as

$$
A^{L}=A^{d} \quad\left(d \in N_{R} \text { and } d \notin N_{U-R}, L R\right)
$$

where $N_{R}$ is the set of all stations of line $R, N_{L}$ represents the set of stations on link $L$, and $U$ denotes all the lines of a rail transit network. 


\subsection{Urban Rail Transit Network Accessibility under Line(s) Failure}

Urban rail transit line is a constitution of stations and links whose failure could be described by simultaneous failures of the stations and links of a line. Based on network accessibility under link failure, rail network accessibility under line failure could be measured as

$$
A^{R}=\sum A^{d}
$$

where $A^{R}$ denotes the rail network accessibility when line(s) $R$ is failed, $d \in N_{R}$ if stations on line $R$ are disrupted, and $d \in N_{R}$ and $d \notin N_{U-R}$ if stations on line $R$ are failed but its transfer stations are still working for other lines.

Based on Equations (8)-(11), rail transit network accessibility changes could be measured with scenarios of single or multiple network elements disruptions. Criticality of disrupted station(s), $\operatorname{link}(\mathrm{s})$, and lines(s) could also be calculated and compared regarding the changes of network accessibility, and thus critical rail transit infrastructures would be identified and prioritized.

\section{Example Problem}

The above methodology is described with an example problem as follows. The example network is shown in Figure 1a, consisting of five bidirectional rail transit lines and six stops. The characteristics of each line (speed, time headway, capacity, and operation frequency) and station (departure and arrival passengers and number of bus stops around the station) are shown in the Figure 1. The origin-destination (OD) passenger flows between stations are also given in Figure 1b. Ground buses running parallel to each rail line are available. It is assumed that disruptions occur in an emergency, passengers in the transit network could not change origins and destinations but routes and modes, and thus there is no change in the departure and arrival passengers for stations within a very short time period after disruptions. The travel costs are defined as the total travel time of rail transit and bus transit consisting of in-vehicle travel time, transfer time, and time headway, which are formulated as

$$
\begin{aligned}
& F R_{i j}=T I V_{i j}^{R}+\sum_{s} T R_{S}\left(T T_{s}^{R}+T H_{s}^{R}\right)(s \geq 1) \\
& F B_{i j}=T I V_{i j}^{B}+\sum_{s} T R_{S}\left(T T_{s}^{B}+T H_{s}^{B}\right)(s \geq 1)
\end{aligned}
$$

where $T I V^{R}{ }_{i j}$ denotes in-vehicle travel cost of rail transit between stations $i$ and $j, T I V^{B}{ }_{i j}$ is in-vehicle travel cost of buses between stations $i$ and $j, T T^{R}$ represents rail transfer time at transfer station(s) $s$ or waiting time at origin rail station $s, T T^{B}{ }_{s}$ is bus transfer time at transfer station(s) $s$ or waiting time at origin station $s, T H^{R}$ shows rail time headway at station(s) $s, T H^{B}{ }_{s}$ denotes bus time headway at station(s) $s$, and $\mathrm{TR}_{\mathrm{S}}$ is a dummy variable and equal to 1 if transfer is needed at station $s$ and 0 if no transfer would made at station $s$. After rail station disruptions, rail passengers would take ground buses as alternative, which share common lines and network with rail transit. The choice of buses follows the shortest-path principle on the transit network.

The above data were input into the proposed methodology, and calculation was conducted in Matlab (R2008a). Methodologies that have been widely used in previous studies such as degree centrality [23], connectivity index [10], and Hansen integral accessibility [17] as shown in Equation (14) were also calculated for the example network. The six stations are assumed to be failed one by one, and then each methodology is calculated for the six stations. A summary of the results is shown in Table 1.

$$
H A_{i}=\frac{\sum_{j} B_{j} f\left(c_{i j}\right)}{\sum_{j} B_{j}}
$$

where $H A_{i}$ is the Hansen integral accessibility index of location $i, B_{j}$ is the attractiveness of location $j$, and $f\left(c_{i j}\right)$ represents the separation between $i$ and $j$ and is usually defined as a function of inversed travel cost between $i$ and $j$. 
(a)

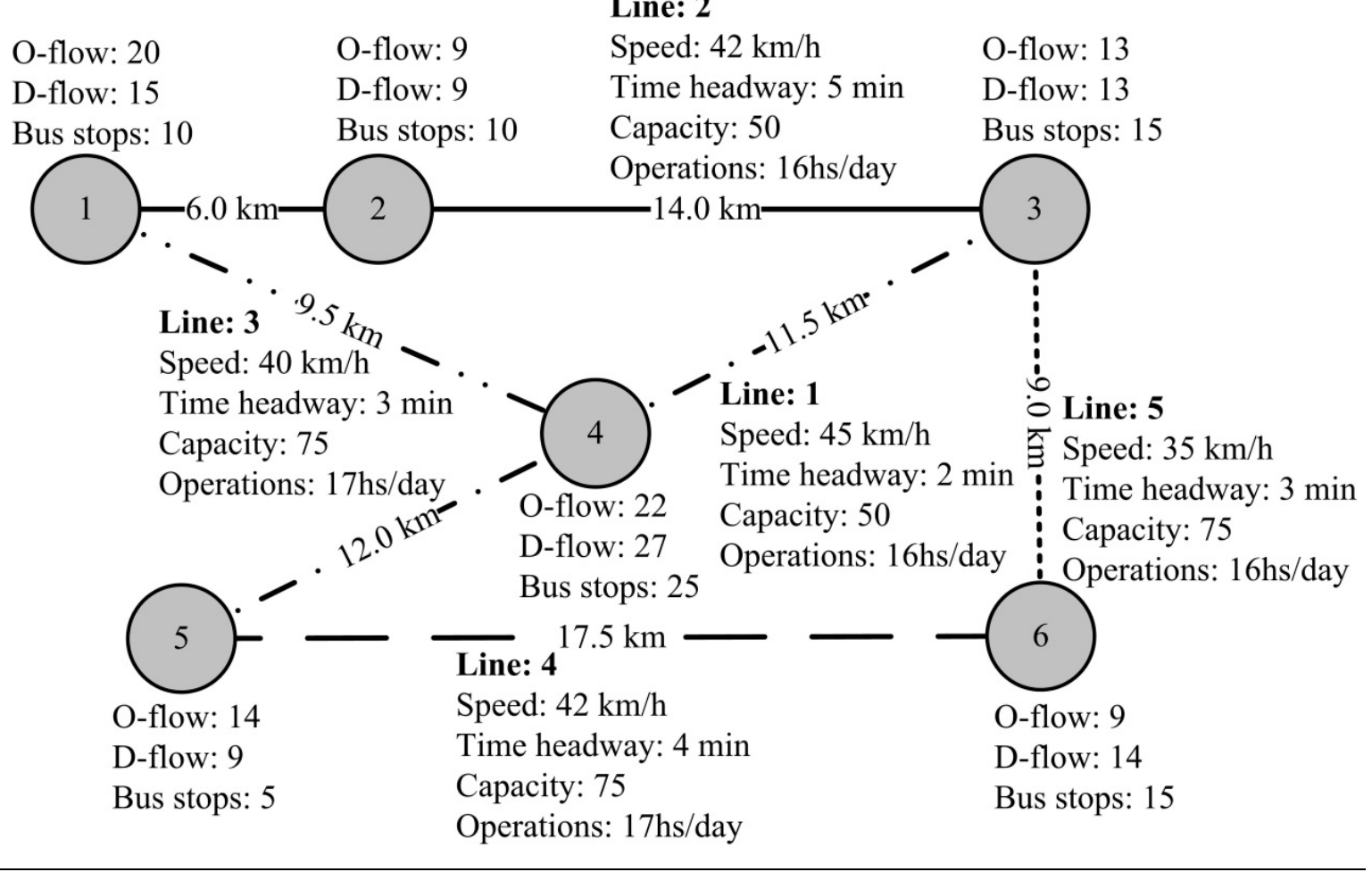

(b)

\begin{tabular}{|c|c|c|c|c|c|c|}
\hline Station ID & $\mathbf{1}$ & $\mathbf{2}$ & $\mathbf{3}$ & $\mathbf{4}$ & $\mathbf{5}$ & $\mathbf{6}$ \\
\hline $\mathbf{1}$ & 0 & 2 & 3 & 9 & 2 & 3 \\
\hline $\mathbf{2}$ & 2 & 0 & 1 & 4 & 1 & 1 \\
\hline $\mathbf{3}$ & 3 & 1 & 0 & 5 & 1 & 2 \\
\hline $\mathbf{4}$ & 6 & 3 & 5 & 0 & 3 & 5 \\
\hline $\mathbf{5}$ & 3 & 1 & 2 & 5 & 0 & 2 \\
\hline $\mathbf{6}$ & 2 & 1 & 1 & 4 & 1 & 0 \\
\hline
\end{tabular}

Figure 1. (a) Example of the urban rail transit system, (b) OD flows between transit stations.

Table 1. Comparison of rail station failure measures for vulnerability analysis.

\begin{tabular}{|c|c|c|c|c|c|c|c|}
\hline \multirow{2}{*}{ Measure } & \multicolumn{6}{|c|}{ Station Values } & \multirow[t]{2}{*}{$\begin{array}{c}\text { Most Affected } \\
\text { Working Stations }\end{array}$} \\
\hline & 1 & 2 & 3 & 4 & 5 & 6 & \\
\hline Connectivity index & 1.33 & 0.30 & 3.06 & 1.37 & 2.95 & 1.62 & $\mathrm{~N} / \mathrm{A}$ \\
\hline Hansen integral accessibility & 75.58 & 53.52 & 86.01 & 134.55 & 70.45 & 59.02 & Available \\
\hline Proposed accessibility approach & 0.686 & 0.752 & 0.838 & 0.970 & 0.800 & 0.798 & Available \\
\hline
\end{tabular}

The widely adopted degree centrality method only considers the network topology characteristics, and thus needs less data and computation time. As a result, stations 3 and 4 with the same topology have the same values and are both identified as the most important stations. Other stations are calculated with values of 0.4 . This method fails to include passengers and transit vehicle characteristics of a rail transit system and would reach inaccurate results. The connectivity method goes one step further by addressing the transit vehicle characteristics such as capacity, frequency, and speed. 
As shown in Table 1, station 3 is calculated as the most important station followed by stations 5, 6, 4, and so on. However, station 4 has much more OD flows than station 3 , and thus more people would be affected when station 4 is failed. The connectivity index still ignores passenger distribution on the network since the consequences of a disruption event are normally evaluated by the number of people affected. Furthermore, the above two methods provide no information about the impacts on other working stations if a station is disrupted. The Hansen integral accessibility method considering the importance of passenger generation stations and the impedance between generation and attraction stations could measure the impacts on other working stations and identify the most affected working stations. But this accessibility index does not include the importance of attraction stations and the availability of other transit services. Under this method, the individual value of each station could provide rare information until compared with values of other stations. The above disadvantages are addressed and improved with the proposed station-based accessibility approach. For example, the Hansen integral accessibility concludes that station 1 is more important than station 5 under disruptions, but station 1 has more bus stops and its vulnerability would decrease with the availability of more bus alternatives than station 5 . This reaches the same conclusion as the proposed method that station 5 is more important and vulnerable as shown in Table 1.

\section{Case Study}

The proposed methodology is applied to the urban rail transit network of Shenzhen, China. The accessibility-based network vulnerability approach is detailed based on station failures on SURTN since link and line failures are calculated based on station failure in the methodology.

\subsection{Case Study Description}

With the third public transport network in China, Shenzhen has a transit ridership of over 10.5 million per day. Shenzhen bus transit operates 919 bus routes with a daily ridership of 5.9 million. Consisting of 5 lines and 118 stations including 13 transfer stations, SURTN has a length of $178.0 \mathrm{~km}$ and ranks sixth in the country. However, it has the fourth rail transit ridership in China with nearly 3.0 million passengers per day after Beijing, Shanghai, and Guangzhou. The peak day rail ridership in Shenzhen would reach 3.5 million. With another 6 lines under construction, SURTN will be extended to 11 lines with a total length of $434.9 \mathrm{~km}$ in 2020. As a job-immigrant city in China, Shenzhen's rail transit is expected to play a more and more important role in people's daily travel. As shown in Figure 2, passenger flow on SURTN is mainly distributed on the southeastern part of the network, and the network would become vulnerable with such large passenger volume under disruptions.

\subsection{Data}

In order to analyze the vulnerability of SURTN under station failures, the following network and passenger flow data are used. The urban rail transit network of Shenzhen with stations and links is shown in Figure 2 for the year of 2013. The network for analysis also contains the Shenzhen bus transit network in the year. The station data include average daily OD trip matrix between rail stations in 2013 and the number of bus stops within $600 \mathrm{~m}$ of rail stations [30]. The candidate rail stations for analysis are selected based on the station OD passengers and the station location on the network, that is, stations with large passenger volume, transfer stations, and stations far away from city center but having a relative high ridership are chosen as candidate stations for analysis. The travel time of rail transit includes in-vehicle travel time, transfer time, and vehicle time headway. Ground buses share the same transit network with rail transit, and passengers of closed stations would choose buses based on the shortest-path principle on the transit network. This study attempts to calculate network performance under emergent incidences such as vehicle breakdown, signal failure, terrorist attacks, and so on, and thus OD trips are assumed to be the same before and after disruptions. 


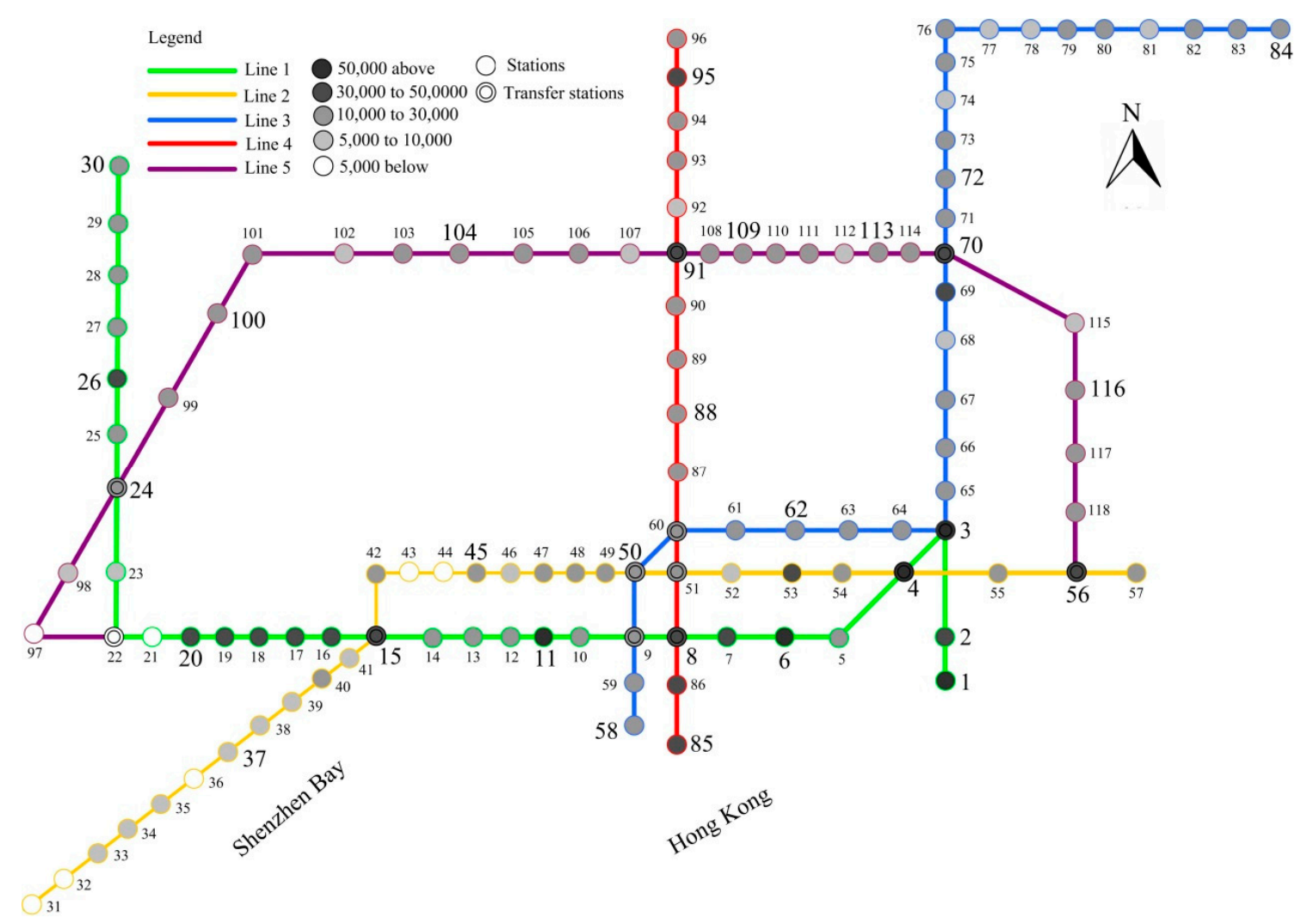

Figure 2. Shenzhen urban rail transit network and passenger volume distribution.

\section{Results and Discussion}

As shown by the IDs with large font size in Figure 2, 30 stations were chosen for analysis. The stations were assumed to be disrupted individually, and station-based network accessibility was calculated under each disruption. The consequence of a station failure is measured with network-wide accessibility reduction compared with its original value of 1 . Multiple failures of stations were then analyzed for the network. The calculation of each disruption scenario consumes $30 \mathrm{~s}$ including $4 \mathrm{~s}$ of the network accessibility calculation in Matlab. The calculation results are shown as follows.

\subsection{Measuring Network Accessibility under Individual Station Failures}

Network accessibility of SURTN was calculated for each of the 30 station failure scenarios, and results are shown in Figure 3. Among all the candidate stations, the failure of station 4 would result in the most network accessibility reduction. Located in the central business district, station 4 has the most passenger volume among all the rail stations in Shenzhen, but does not have the highest bus availability, that is, bus stop and passenger volume ratio. When station 4 is disrupted, a large volume of affected passengers could not find enough bus alternatives to evacuate, and thus poses the most risk to the rail transit network. Following station 4, stations 3, 11, 26, 6, and 1 also cause high accessibility reduction if disrupted. All of these stations are on Line 1, which was built the earliest and goes through the most developed area of Shenzhen City. Station 62 is proven to be the least important station whose failure causes the least network accessibility reduction. Situated in a less populated area of the city, station 62 has only $30 \%$ of rail ridership but five times the bus availability of station 4, which would account for the least importance of station 62 . The failure of station 37 causes a small network accessibility reduction, which may be due to its low ridership as it has only $10 \%$ of the ridership of station 4 . Substantial accessibility reductions could be observed for most of the transfer stations, since most of them have relative high ridership. However, failures of transfer stations 50 and 24 generate low network accessibility reductions that are even lower than non-transfer stations. 
Station 24 has a relatively low ridership, and as a suburban station its importance would be low under disruptions. Serving the central area of the city, station 50 has higher ridership and bus availability than station 24. Particularly, the OD trips of station 50 are mainly distributed among the surrounding stations, and the short distance trips would be less affected once station 50 is closed. Station 30 has the most importance under failure, comparing the rank based on passenger volume. One reason would be the low bus availability around the station, and the other could be explained by its widely distributed OD flows, which could be seriously affected for long-distance bus alternative travels if station 30 is disrupted. These passenger flow and bus alternative characteristics could be captured with the proposed methodology. It is worth noting that all the disrupted stations are still accessible but have substantial reductions (more than $80 \%$ ) in their accessibility.

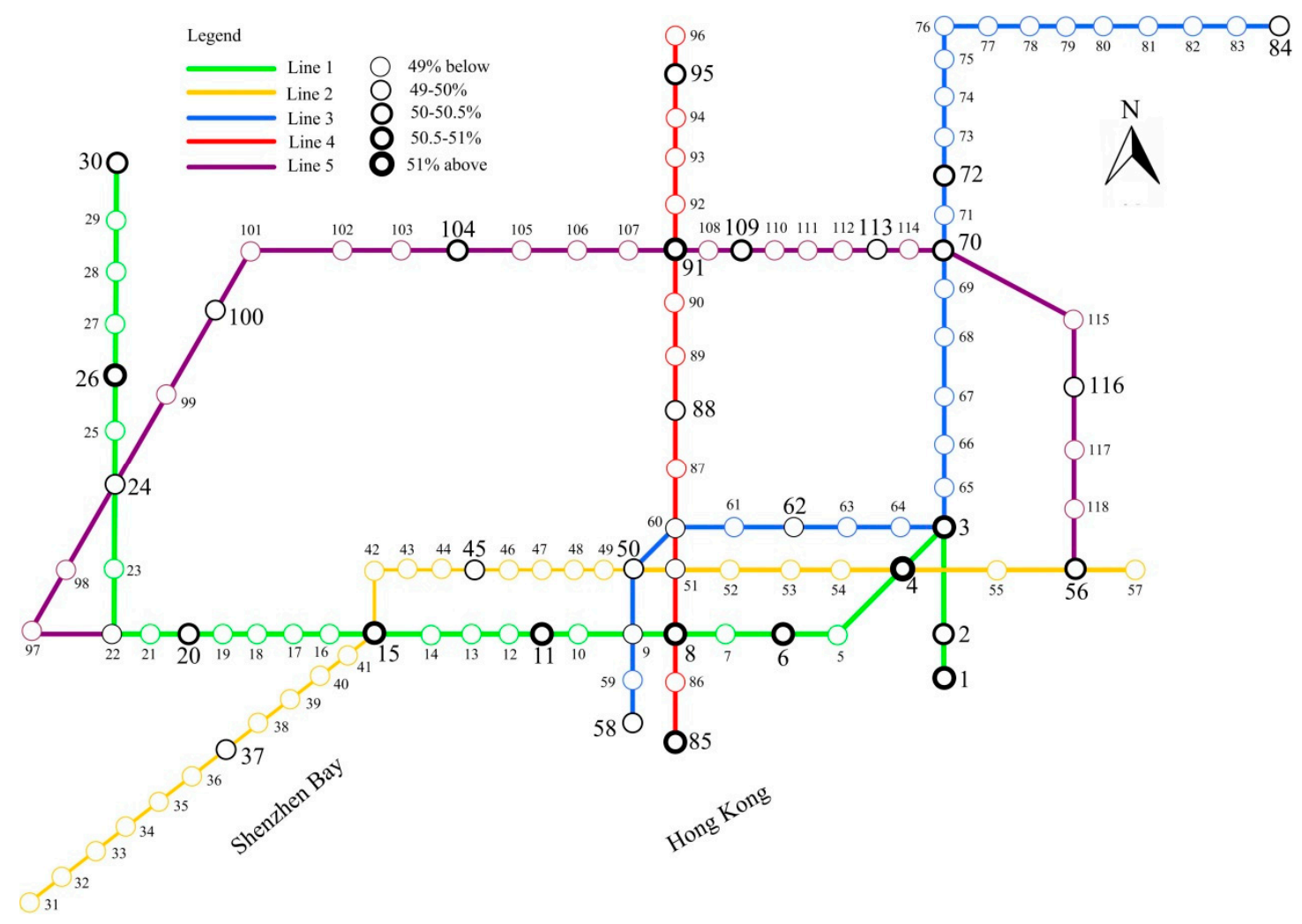

Figure 3. Network-wide accessibility reduction under failure of 30 stations.

The top-15 stations whose failures result in the greatest accessibility reductions are shown in Table 2. Passenger volume of each station is ranked for the top- 15 stations out of the 30 stations. The network accessibility values do not vary too much under these station failures, however, the station importance rank is different to the rank of original passenger volume. Stations 4 and 3 are shown to be the most important stations and no differences are reported under both ranks. As discussed above, the greatest difference between the two ranks is observed under station 30 followed by stations 70 and 26. Such stations should be paid particular attention as although they may not seem very important under normal situations, they may seriously affect network accessibility if they fail, or inversely may show high importance levels normally but are not that critical once disrupted. Once a station has failed, some working stations could be affected to different extents because of network topology and passenger flow interrelationships between them. The five most affected working stations under each station failure are also identified in Table 2. These stations mainly belong to the same rail line as the disrupted stations, which demonstrates that most indirect impacts of a station failure are imposed on stations sharing the same line. Moreover, the most affected working stations include not only surrounding stations of the disrupted station but also far away stations with large passenger flows. 
Station 86 is shown to be the most affected station under failures of stations 8 and 15, as the OD trips of station 86 to and from stations 8 and 15 are the most among other stations. Station 18 turns out to be the most affected station if station 3,11,20, or 26 is disrupted. This is because the OD trips of station 18 between stations 20 and 26 are almost ten times higher than that of other stations, and the bus passenger volume ratios are low for stations 3 and 11, thus once disrupted, travel costs from stations 3 and 11 to station 18 would be high. Additionally, stations 28 and 91 are also shown to be the five most affected stations under many station failures, and these stations should be paid more attention under disruptions.

Table 2. Top-15 stations with most impacts on network accessibility.

\begin{tabular}{lllll}
\hline Station ID & $\begin{array}{l}\text { Passenger } \\
\text { Volume Rank }\end{array}$ & $\begin{array}{l}\text { Network Accessibility after } \\
\text { Station Disruption (\%) }\end{array}$ & $\begin{array}{l}\text { Accessibility } \\
\text { Reduction Rank }\end{array}$ & $\begin{array}{l}\text { Most Affected } \\
\text { Working Stations }\end{array}$ \\
\hline 4 & 1 & 88.623 & 1 & $5,18,28,94,116$ \\
3 & 2 & 89.058 & 2 & $18,71,94,90,28$ \\
6 & 3 & 89.204 & 5 & $8,91,7,30,18$ \\
1 & 4 & 89.337 & 6 & $28,18,94,5,3$ \\
11 & 5 & 89.297 & 3 & $18,91,12,116,28$ \\
8 & 6 & 89.381 & 7 & $86,6,18,90,91$ \\
15 & 7 & 89.789 & 10 & $86,30,18,90,5$ \\
26 & 8 & 89.307 & 4 & $18,28,91,30,116$ \\
85 & 9 & 89.285 & 8 & $91,18,90,86,94$ \\
70 & 11 & 89.681 & 15 & $91,118,116,117,3$ \\
91 & 12 & 89.348 & 9 & $116,86,90,94,71$ \\
109 & 13 & 89.664 & 12 & $91,118,117,18,28$ \\
20 & 14 & 89.380 & 11 & $18,28,30,17,3$ \\
72 & 17 & 89.726 & 14 & $91,18,66,117,28$ \\
30 & 18 & 89.633 & 13 & $28,18,116,91,24$ \\
\hline
\end{tabular}

\subsection{Network Accessibility under Multiple Station Failures}

The proposed methodology is applied to simultaneous multiple station failures on SURTN. Six scenarios are proposed, and the network accessibility is calculated for each scenario in Table 3. As shown in the Table 3, scenarios with a large passenger volume do not necessarily cause high network accessibility reduction, and scenarios with three stations normally have a greater impact on network accessibility than those with two stations. The five most affected working stations under each scenario are also included in the results. Similar to individual station failures, the most affected working stations are mainly those on the same line with disrupted stations. Stations 18 and 19 are shown to be the most affected under four multiple station failure scenarios, and station 18 appears in three of the six scenarios. This could be explained by the high OD trip distributions of station 18 on stations in Line 1 and those in the southeast of the network, and when stations in these areas fail the accessibility of station 18 is significantly affected. Together with the results in Table 2, it could be concluded that stations 116, 117, and 118 are vulnerable to station failures on the same line, especially to disruptions to transfer stations, since they show high accessibility reductions under these failures.

Table 3. Network accessibility under multiple station failures.

\begin{tabular}{lllll}
\hline Station IDs & $\begin{array}{l}\text { Passenger } \\
\text { Volume Rank }\end{array}$ & $\begin{array}{l}\text { Network Accessibility } \\
\text { after Disruptions (\%) }\end{array}$ & $\begin{array}{l}\text { Accessibility } \\
\text { Reduction Rank }\end{array}$ & $\begin{array}{l}\text { Most Affected } \\
\text { Working Stations }\end{array}$ \\
\hline 3,4 & 1 & 71.766 & 3 & $18,94,5,24,90$ \\
$11,45,70$ & 2 & 64.802 & 1 & $19,40,91,116,118$ \\
$8,30,50$ & 3 & 64.822 & 2 & $19,86,91,90,92$ \\
1,20 & 4 & 72.626 & 4 & $18,28,25,24,3$ \\
56,91 & 5 & 72.880 & 5 & $116,117,118,54,114$ \\
24,26 & 6 & 73.043 & 6 & $91,30,28,18,113$ \\
\hline
\end{tabular}


Urban rail network accessibility under link and line failures could be measured based on station failures, that is, individual or multiple station disruptions. The vulnerability of rail transit networks should also include the probability of station, link, or line failure. Network vulnerability is the product of failure probability and network accessibility reduction. Additionally, types of disruption and their duration should also be included in the vulnerability analysis. More discussions on the probability calculation of urban rail transit disruptions can be found in Cats et al. and $\mathrm{Lu}[12,21]$.

\section{Conclusions}

Urban rail transit network vulnerability has largely focused on network topology issues in previous studies, and passenger flow characteristics should be included in vulnerability approaches considering the influence of these characteristics on network performance.

This study presents and applies an accessibility-based vulnerability method to explicitly account for the passenger flow characteristics under conditions of station(s), link(s), and line(s) disruptions. The vulnerability approach is presented with the help of an example network. Distinct results are shown between the proposed method and existing indices in the literature. The proposed approach presents a more accurate representation by capturing the passenger flow distribution and ground bus alternative. Most topology-based methods could not provide further information except for the evaluated station, while the proposed approach could assess impacts not only on the network but also on other stations. The case study on the rail transit network of Shenzhen, China further demonstrated that the consequences of station disruptions on network performance differ obviously with different passenger flow distributions and bus alternative availability.

The main contribution of this approach is that it includes the importance of the destination station and weight of origin station while considering alternative public transport networks, and thus helps to understand the mechanism of passenger flow distribution characteristics on the rail transit network in the network vulnerability analysis. The methodology could be applied to failures of station, link, and line as well as multiple disruptions of the network elements. Besides the assessment of network vulnerability, disruption impacts on other working stations could also be identified with this methodology. These would be important for rail transit network vulnerability analysis, especially in cities of developing countries with large numbers of rail passengers and increasing passenger demand.

The results of the proposed measure could be implemented by public transport planners and operators to design and manage a resilient urban rail transit network. The vulnerability of the network could be reduced with network plan and design measures during the rail transit network expansion, especially for the most important stations. Bus and other transit networks should be planned in coordination with the urban rail transit network to enhance the robustness of the transit network as a whole. Under emergencies of rail transit, bridging bus design and operation decisions could be made based on the identified impacts of disrupted stations on the network. Additional measures taken for the disrupted rail stations, ground bus bridging, and passenger evacuation plans could also be adopted for the most affected working stations.

The main limitation of the presented approach is the higher data requirements compared to previous methods. Fortunately, these passenger flow data are widely available from multiple sources in public transport. The process of capturing these data and calculations would consume a little more time than the network topology methods, but the total time for each scenario is only half a minute, which would be acceptable in order to gain more in-depth results. An additional limitation relates to the behavioral assumption that all the affected passengers would take a bus as the alternative, but in reality, some may take other transit modes such as taxi and others may wait until disruptions are fixed. If disruptions continue for a very long time, the changes in rail transit demand should be addressed. Detailed passenger behavioral analyses at different travel stages with revealed preference and stated preference data under different rail disruptions would benefit the analysis of rail transit network vulnerability within multi-modal public transport networks. 
Author Contributions: Q.-C.L. and S.L. conceived and designed the whole research; Q.-C.L. analyzed the data and wrote the paper, S.L. proposed the research framework. Both authors have read and approved the final manuscript.

Funding: This research was funded by the Fundamental Research Funds for the Central Universities, CHD (300102329302) and the National Natural Science Foundation of China (51408356).

Acknowledgments: The authors would like to thank the Transport Commission of Shenzhen Municipality for providing urban rail transit passenger data.

Conflicts of Interest: The authors declare no conflict of interest. The founding sponsors had no role in the design of the study; in the collection, analyses, or interpretation of data; in the writing of the manuscript, and in the decision to publish the results.

\section{References}

1. Rodríguez-Núñez, E.; García-Palomares, J.C. Measuring the vulnerability of public transport networks. J. Transp. Geogr. 2014, 35, 50-63. [CrossRef]

2. Loo, B.P.Y.; Leung, K.Y.K. Transport resilience: The Occupy Central Movement in Hong Kong from another perspective. Transp. Res. Part A Policy Pract. 2017, 106, 100-115. [CrossRef]

3. Cox, A.; Prager, F.; Rose, A. Transportation security and the role of resilience: A foundation for operational metrics. Transp. Policy 2011, 18, 307-317. [CrossRef]

4. Van Oort, N. Incorporating service reliability in public transport design and performance requirements: International survey results and recommendations. Res. Transp. Econ. 2014, 48, 92-100. [CrossRef]

5. Jenelius, E.; Petersen, T.; Mattsson, L.-G. Importance and exposure in road network vulnerability analysis. Transp. Res. Part A 2006, 40, 537-560. [CrossRef]

6. Chen, A.; Yang, C.; Kongsomsaksakul, S.; Lee, M. Network-based accessibility measures for vulnerability analysis of degradable transportation networks. Netw. Spat. Econ. 2007, 7, 241-256. [CrossRef]

7. Lu, Q.C.; Peng, Z.R. Vulnerability analysis of transportation network under the scenarios of sea level rise. Transp. Res. Rec. J. Transp. Res. Board 2011, 2263, 174-181. [CrossRef]

8. Taylor, M.A.P.; Susilawati, S. Remoteness and accessibility in the vulnerability analysis of regional road networks. Transp. Res. Part A 2012, 46, 761-771. [CrossRef]

9. Mattsson, L.-G.; Jenelius, E. Vulnerability and resilience of transport systems- A discussion of recent research. Transp. Res. Part A 2015, 81, 16-34. [CrossRef]

10. Mishra, S.; Welch, T.F.; Jha, M.K. Performance indicators for public transit connectivity in multi-modal transportation networks. Transp. Res. Part A 2012, 46, 1066-1085. [CrossRef]

11. Cats, O.; Jenelius, E. Planning for the unexpected: The value of reserve capacity for public transport network robustness. Transp. Res. Part A 2015, 81, 47-61. [CrossRef]

12. Cats, O.; Yap, M.; Van Oort, N. Exposing the role of exposure: Public transport network risk analysis. Transp. Res. Part A 2016, 88, 1-14. [CrossRef]

13. Jiang, R.; Lu, Q.C.; Peng, Z.R. A station-based rail transit network vulnerability measure considering land use dependency. J. Transp. Geogr. 2018, 66, 10-18. [CrossRef]

14. Sohn, J. Evaluating the significance of highway network links under the flood damage: An accessibility approach. Transp. Res. Part A 2006, 40, 491-506. [CrossRef]

15. Chen, X.Z.; Lu, Q.C.; Peng, Z.R.; Ash, J.E. Analysis of transportation network vulnerability under flooding disasters. Transp. Res. Rec. 2015, 2532, 37-44. [CrossRef]

16. Bell, M.G.H.; Kanturska, U.; Schmöcker, J.D.; Fonzone, A. Attacker-defender models and road network vulnerability. Philos. Trans. R. Soc. A 2008, 366, 1893-1906. [CrossRef]

17. Taylor, M.A.P.; D'Este, G.M.; Sekhar, S.V.C. Application of accessibility based methods for vulnerability analysis of strategic road networks. Netw. Spat. Econ. 2006, 3, 267-291. [CrossRef]

18. Lu, Q.C.; Peng, Z.R.; Zhang, J. Identification and prioritization of critical transportation infrastructure: A case study of coastal flooding. J. Transp. Eng.-ASCE 2015, 141, 04014082. [CrossRef]

19. Knoop, V.L.; Snelder, M.; Van Zuylen, H.J.; Hoogendoorn, S.P. Link-level vulnerability indicators for real-world networks. Transp. Res. Part A 2012, 46, 843-854. [CrossRef]

20. Chen, B.Y.; Lam, W.H.K.; Sumalee, A.; Li, Q.; Li, Z.C. Vulnerability analysis for large-scale and congested road networks with demand uncertainty. Transp. Res. Part A 2012, 46, 501-516. [CrossRef] 
21. Derrible, S.; Kennedy, C. The complexity and robustness of rail networks. Physica A 2010, 389, 3678-3691. [CrossRef]

22. Dimitrov, S.D.; Ceder, A. A method of examining the structure and topological properties of public-transport networks. Physica A 2016, 451, 373-387. [CrossRef]

23. Zhang, X.; Miller-Hooks, E.; Denny, K. Assessing the role of network topology in transportation network resilience. J. Transp. Geogr. 2015, 46, 35-45. [CrossRef]

24. Lu, Q.C. Modeling network resilience of rail transit under operational incidents. Transp. Res. Part A Policy Pract. 2018, 117, 227-237. [CrossRef]

25. De-Los-Santos, A.; Laporte, G.; Mesa, J.A.; Perea, F. Evaluating passenger robustness in a rail transit network. Transp. Res. Part C 2012, 20, 34-46. [CrossRef]

26. Cats, O.; Jenelius, E. Dynamic vulnerability analysis of public transport networks: Mitigation effects of real-time information. Netw. Spat. Econ. 2014, 14, 435-463. [CrossRef]

27. Bhat, C.; Handy, S.; Kockelman, K.; Mahmassani, H.; Gopal, A.; Srour, I.; Weston, L. Development of an Urban Accessibility Index: Formulations, Aggregation, and Application; Center for Transportation Research, The University of Texas at Austin: Austin, TX, USA, 2002.

28. Litman, T. Evaluating Accessibility for Transportation Planning: Measuring People's Ability to Reach Desired Goods and Activities. 2016. Available online: http:/ / www.vtpi.org/access.pdf (accessed on 1 December 2018).

29. Nassir, N.; Hickman, M.; Malekzadeh, A.; Irannezhad, E. A utility-based travel impedance measure for public transit network accessibility. Transp. Res. Part A 2016, 88, 26-39. [CrossRef]

30. Jun, M.J.; Choi, K.; Jeong, J.E.; Kwon, K.H.; Kim, H.J. Land use characteristics of subway catchment areas and their influence on subway ridership in Seoul. J. Transp. Geogr. 2015, 48, 30-40. [CrossRef]

(C) 2019 by the authors. Licensee MDPI, Basel, Switzerland. This article is an open access article distributed under the terms and conditions of the Creative Commons Attribution (CC BY) license (http:/ / creativecommons.org/licenses/by/4.0/). 